\title{
Diphtheroids as a cause of endocarditis in a haemodialysis patient
}

\author{
Rajeev Peeyush Nagassar, ${ }^{1}$ Alison Merle Nicholson, ${ }^{1}$ Winston Williams, ${ }^{2}$ Roma Jaanki \\ Bridgelal-Nagassar ${ }^{3}$
}

${ }^{1}$ Microbiology Department, University Hospital Of the West Indies, Kingston, Jamaica;

${ }^{2}$ Medicine Department, University Hospital Of the West Indies, Kingston, Jamaica;

${ }^{3}$ Community Health Department, The University Of the West Indies, Kingston, Jamaica

Correspondence to Dr Rajeev Peeyush Nagassar, rpnagassar@gmail.com

\section{Summary}

The authors report a fatal case of Corynebacterium sp. endocarditis. Corynebacterium spp. are non-sporulating, pleomorphic Gram-positive bacilli. In particular the authors have identified a species of Corynebacterium very closely related to $C$ striatum. This is $C$ simulans. The authors were able to identify the genus and species using various phenotypic tests. Highlighted here is the importance of identifying diphtheroids as a significant pathogen in the appropriate setting and the need to start antibiotic therapy if this is suspected.

\section{BACKGROUND}

Diphtheroids are commonly isolated in laboratory cultures but are often regarded as contaminants. However evidence has been available to suggest that these organisms can cause a wide range of infections. ${ }^{1}$ These aerobic, nonsporulating, pleomorphic Gram-positive bacilli are usually commensals of the skin and mucous membranes. ${ }^{1}$ In fact, infective endocarditis caused by Corynebacterium spp. was recognised as early as 1932 , but diphtheroids are still disregarded when isolated. ${ }^{2-5}$ Here, we present a fatal case of infective endocarditis due to $C$ simulans in a haemodialysis patient from Jamaica.

\section{CASE PRESENTATION}

A middle aged male patient was first seen at the emergency department of a hospital in the West Indies. The patient had been transferred from another urban hospital for evaluation of his dialysis catheter. He was on regular haemodialysis treatment for 1 year via a right tunnelled, internal jugular catheter.

He was admitted to the hospital with a history of fever for 1 day, cough for 1 week productive of white sputum and diarrhoea for 2 weeks. He had watery diarrhoea three to four times daily with no blood in the stools. He complained of shortness of breath at rest but no history of chest pain. His past medical history included hypertension.

His family history was unknown and he could not remember the names of his medication. He lived with his wife and did not smoke or drink alcohol.

On examination he was in no obvious cardiopulmonary distress. The patient was afebrile and examination of his respiratory, abdominal and central nervous systems revealed no significant abnormality. However cardiovascular examination revealed a pansystolic murmur at the apex which did not radiate.

Blood from the catheter and peripheral veins were sent to the microbiology laboratory for culture and sensitivity testing. Four sets of peripheral blood cultures from different sites and at different times were taken. The two sets of catheter blood cultures were also taken at different times. Stool was cultured and examined for ova, cysts and parasites.

The patient was diagnosed with end stage renal disease chest x-ray confirmed cardiomegaly. Gram-positive bacilli with catheter sepsis and started empirically on coamoxiclav 1.2 grams intravenously every (q) $24 \mathrm{~h}$ (four times a day) and ceftazidime $1 \mathrm{~g}$ intravenously once daily. The dosages were renally adjusted. Other medications included hydralazine $25 \mathrm{mg}$ orally (po) three times a day, ferrous sulphate two tablets po twice daily, folic acid 5 mg po once daily and calcium carbonate two tablets po three times a day and he was kept on a renal diet and fluid restriction. These medications were started based on his presenting symptoms and treatment at the previous hospital.

ECG showed left ventricular hypertrophy and bacteria was isolated from both peripheral and catheter blood samples. The bacteria was identified as diphtheroids and as a result regarded as contaminants so the patient was discharged from hospital 3 days after admission with a plan for medical review in one week. No further identification was done on these specimens, especially since they were considered insignificant. He was not considered for cardiology evaluation of possible infective endocarditis as the differential diagnosis did not include infective endocarditis at this time. He was also not considered for echocardiogram evaluation.

On routine review of this patient 1 week later, he complained of fever, cough, exertional dyspnoea, chills and rigors. He had orthopnoea, paroxysmal nocturnal dyspnoea and occasional bilateral leg swelling. On examination he was febrile and in moderate cardiopulmonary distress. His jugular venous pressure was elevated and the apex beat was displaced. He had a grade $4 / 5$ pansystolic murmur at the apex which radiated to the axilla and a grade $3 / 5$ late diastolic murmur over the aortic area. In addition, patient 
had hepatomegaly and examination of his respiratory system revealed bilateral basal crepitations.

$\mathrm{He}$ was diagnosed with unresolved dialysis catheter sepsis and acute left ventricular failure. The patient was started on ceftriaxone $1 \mathrm{~g}$ intravenously once daily. A chest x-ray showed right mid and lower zone opacities indicating a lower respiratory tract infection and the patient's antibiotic treatment was changed to ceftazidime $1 \mathrm{~g}$ intravenously once daily and ciprofloxacin $500 \mathrm{mg}$ po twice daily.

The patient showed no improvement and his antibiotics were changed empirically to co-amoxiclav $1.2 \mathrm{~g}$ intravenously four times a day and levofloxacin $750 \mathrm{mg}$ intravenously four times a day. He was referred to cardiology services for further management of infective endocarditis.

\section{INVESTIGATIONS}

The echocardiogram report showed that the posterior mitral leaflet had on its inflow surface a large mass 2.16 $\mathrm{mm}$ by $1.36 \mathrm{~mm}$. This could have been vegetation. There was severe mitral regurgitation into a moderately dilated left atrium. There was also severe tricuspid regurgitation into a severely dilated right atrium and the estimated pulmonary systolic pressure was $73 \mathrm{~mm} \mathrm{Hg}$. The left ventricular systolic function was moderately reduced at $37 \%$ ejection fraction. The right ventricular systolic function was also moderately reduced. The semilunar valves functioned normally. The septa were intact and great vessels were normal. The patient showed marked deterioration from the previous admission. A chest $\mathrm{x}$-ray showed right mid and lower zone opacities.

Repeat blood cultures were positive using the automated Bactec system with a total of six peripheral and catheter blood specimens growing Gram-positive bacilli after 24 $\mathrm{h}$ to 3 days. The presence of multiple positive cultures prompted the laboratory to do antibiotic susceptibility testing. The organism was found to be uniformly susceptible to gentamicin and vancomycin in the peripheral blood cultures. The catheter blood cultures showed susceptibility to gentamicin, vancomycin and co-amoxiclav.

Four peripheral blood culture samples were received, two were positive for Gram-positive bacilli after $24 \mathrm{~h}$ and the other two after $48 \mathrm{~h}$. Two catheter blood samples were positive for Gram-positive bacilli within $24 \mathrm{~h}$.

It is important to note that on first admission the patient also grew Gram-positive bacilli in the blood but this was thought to be insignificant.

\section{Microbiological investigations}

The Gram-positive bacilli isolated were characterised using the catalase reaction and fermentation of the sugars dextrose and sucrose as well as additional tests. ${ }^{1}$ These results narrowed down identity of the organisms to $C$ striatum or $\mathrm{C}$ simulans. Tests such as growth at $20^{\circ} \mathrm{C}$ and ethylene glycol acidification confirmed the identity of the organism as $C$ simulans. ${ }^{6-8}$ After reviewing the article by Wattiau et al it was found that the phenotypic tests performed were adequate. ${ }^{6}$ Molecular identification was not done. This would have been a disadvantage as molecular identification is more reliable for confirmation of the organism. Hence we emphasise the importance of considering diphtheroids as pathogens and not just $C$ simulans.

\section{DIFFERENTIAL DIAGNOSIS}

Unresolved dialysis catheter sepsis and acute left ventricular failure was entertained as a diagnosis as the patient presented previously with symptoms of infection and the catheter was thought to be the source. However after interspecialty consultation it was decided the patient had infective endocarditis, pulmonary hypertension, dilated cardiomyopathy and end stage renal disease.

\section{TREATMENT}

\section{Microbiological treatment}

The Kirby-Bauer disc diffusion method was used to test antibiotic susceptibility. The antibiogram for the isolates from peripheral blood culture were susceptibile to gentamicin and vancomycin. While the catheter blood samples showed sensitivity to gentamicin, vancomycin and co-amoxiclav.

Empiric treatment with co-amoxiclav $1.2 \mathrm{~g}$ intravenously once daily (adjusted for renal impairment) and levofloxacin $750 \mathrm{mg}$ intravenously four times a day was commenced after the second admission and the patient deteriorated.

There was discussion between microbiology and the attending physicians concerning the need for this patient to be treated with renal doses of gentamicin $60 \mathrm{mg}$ intravenously once daily and vancomycin $1 \mathrm{~g}$ intarvenously on alternate days, however the patient died before this could have been done.

Diuretics, nitrates and other medications for heart failure were not commenced.

\section{OUTCOME AND FOLLOW-UP}

The patient died before appropriate antibiotics could be started.

\section{DISCUSSION}

Diphtheroids are commonly isolated in laboratory cultures but are often regarded as contaminants. This case, along with other cases reported in the literature, highlights the fact that Corynebacterium spp. can be pathogenic. Where multiple peripheral blood cultures are positive for Corynebacterium spp., especially when cultures become positive within $24-48 \mathrm{~h}$, then antibiotic susceptibility testing should be considered and clinical correlation advised with consideration of the modified Duke's criteria. This is important as antibiotic coverage for Corynebacterium spp. may not be provided by empiric antibiotic therapy. In this case, both catheter blood samples were positive within 24 $\mathrm{h}$ and of the four peripheral blood samples, two were positive after $24 \mathrm{~h}$ and the other two after $48 \mathrm{~h}$.

Only a few other cases of infective endocarditis caused by $C$ simulans have been previously reported. ${ }^{9} C$ simulans was first recognised as a new species in 2000 by Wattiau et al. ${ }^{6}$ It is genetically quite similar to $C$ striatum with greater than $98 \%$ gene homology with $16 \mathrm{~S}$ rRNA. It has been shown by Belmares et al that the average age of a patient with $C$ striatum endocarditis is $61.3+/-16.5$ years. ${ }^{2}$ There is a greater predilection for the left side of the heart and there is a statistically significant association with nosocomial risk factors such as the presence of an intravascular access device, dialysis fistula, pacemaker or presence of a prosthetic device other than a valve. ${ }^{2} 10$ This case shows this pattern. $C$ striatum is mentioned because of its high 
genetic homology with $C$ simulans. It should also be noted that some of those organisms classified as $C$ striatum may in fact have been $C$ simulans.

The consistent isolation of Corynebacterium spp. should alert the clinician to a significant clinical finding. ${ }^{11}$ It should be noted that this patient also had the additional complication of having end-stage renal disease, which affected appropriate choice and dosage of antibiotic therapy employed.

In one study $27 \%$ of patients had non-cardiac predisposing factors with chronic haemodialysis and haemodialysis being factors. ${ }^{8}$ In another study, over a quarter of patients with Corynebacterium spp. endocarditis required valve replacement and the death rate was over $40 \% .^{2}$ C simulans has previously been isolated from the blood. ${ }^{12}$

If Corynebacterium spp. endocarditis is suspected, empirical treatment with appropriate antibiotic treatment should be considered, and in cases of renal impairment appropriate renal doses should be started. ${ }^{8} 11$

This case showed that $C$ simulans is a cause of disease and Corynebacterum spp. should be considered as a cause of bacterial endocarditis where there is persistent isolation of these bacteria, with no other bacteria being isolated. ${ }^{2} 8$

\section{Learning points}

- Gram-positive bacteria, especially diphtheroids, in certain patient populations, should be regarded as potential pathogens and cultures should not simply be disregarded as contaminants.

- Haemodialysis patients are susceptible to rare infections.

- Modified Duke's criteria and multiple peripheral blood cultures are important for a microbiological diagnosis of rare causes of endocarditis.

- Multi-disciplinary approach is important for proper patient management, particularly early involvement of cardiologists, infectious diseases specialist and medical microbiologist in suspected cases of infective endocarditis.
Acknowledgements The authors would kindly like to thank Mrs $L$ Rainford for her assistance in this study. The authors would also like to thank Professor John Lindo and Dr Tony Mazzuli for their input. The authors would also like to thank Tricia Day-Williams and the residents of the Department of microbiology.

Competing interests None.

Patient consent Not obtained.

\section{REFERENCES}

1. Funke G, Bernard KA. Coryneform Gram positive rods. In: Murray PR, Baron EJ, Jorgensen JH, Landry ML, Pfaller MA, eds. Manual of Clinical Microbiology. Ninth Edition. Washington DC: ASM Press 2007:485-514.

2. Belmares $\mathbf{J}$, Detterline $S$, Pak JB, et al. Corynebacterium endocarditis species-specific risk factors and outcomes. BMC Infect Dis 2007;7:4.

3. Tow A, Wechsler HF. Diphtheroid bacillus as the cause of acute endocarditis. Am J Dis Child 1932:44:156-61.

4. Leonard A, Raij L, Shapiro FL. Bacterial endocarditis in regularly dialyzed patients. Kidney Int 1973;4:407-22.

5. Martinez-Vea A, Costa J, Garcia C, et al. Corynebacterium group JK endocarditis in a haemodialysis patient. Nephrol Dial Transplant 1993;8:177-9.

6. Wattiau $\mathbf{P}$, Janssens $M$, Wauters $\mathbf{G}$. Corynebacterium simulans sp. nov. a non-lipophilic, fermentative Corynebacterium. Int J Syst Evol Microbiol 2000;50 Pt 1:347-53

7. Wauters G, Van Bosterhaut B, Janssens M, et al. Identification of Corynebacterium amycolatum and other nonlipophilic fermentative corynebacteria of human origin. J Clin Microbiol 1998;36:1430-2.

8. Rufael DW, Cohn SE. Native valve endocarditis due to Corynebacterium striatum: case report and review. Clin Infect Dis 1994;19:1054-61.

9. Markowitz SM, Coudron PE. Native valve endocarditis caused by an organism resembling Corynebacterium striatum. J Clin Microbio 1990;28:8-10.

10. Vanbosterhaut B, Surmont I, Vandeven J, et al. Corynebacterium jeikeium (group JK diphtheroids) endocarditis. A report of five cases. Diagn Microbiol Infect Dis 1989;12:265-8.

11. Knox KL, Holmes AH. Nosocomial endocarditis caused by Corynebacterium amycolatum and other nondiphtheriae corynebacteria. Emerging Infect Dis 2002;8:97-9

12. Bernard KA, Munro $C$, Wiebe $D$, et al. Characteristics of rare or recently described corynebacterium species recovered from human clinical material in Canada. J Clin Microbiol 2002;40:4375-81.

This pdf has been created automatically from the final edited text and images.

Copyright 2012 BMJ Publishing Group. All rights reserved. For permission to reuse any of this content visit http://group.bmj.com/group/rights-licensing/permissions.

BMJ Case Report Fellows may re-use this article for personal use and teaching without any further permission.

Please cite this article as follows (you will need to access the article online to obtain the date of publication).

Nagassar RP, Nicholson AM, Williams W, Bridgelal-Nagassar RJ. Diphtheroids as a cause of endocarditis in a haemodialysis patient. BMJ Case Reports 2012;10.1136/bcr.10.2011.4894, Published XXX

Become a Fellow of BMJ Case Reports today and you can:

- Submit as many cases as you like

- Enjoy fast sympathetic peer review and rapid publication of accepted articles

- Access all the published articles

- Re-use any of the published material for personal use and teaching without further permission

For information on Institutional Fellowships contact consortiasales@bmjgroup.com

Visit casereports.bmj.com for more articles like this and to become a Fellow

Keep up to date with all published cases by signing up for an alert (all we need is your email address) http://casereports.bmj.com/cgi/alerts/etoc 